\title{
RELIABILITY COMPARISC!! OF VARIOUS NUCLEAR PROPULSION CONFIGURATIONS FOR MARS MISSION
}

\author{
D. R. Segna \\ J. E. Dagle \\ W. F. Lyon III
}

January 1992

\author{
Presented at the \\ 9 th Symposium on Space Nuclear \\ Power Systems \\ January 12-16, 1992 \\ Albuquerque, New Mexico \\ Work supported by \\ the U.S. Department of Fnergy \\ under Contract DE-ACO6-76RLO 1830
}

Pacific Northwest Laboratory
Richland, Washington 99352

\section{DISCLAIMER}

\begin{abstract}
This report was prepared as an account of work sponsored by an agency of the United States Government. Neither the United States Gnvernment nor any agency thereof, nor any of their employees, makes any warranty, express or implied, or assumes any legal liability or responsibility for the accuracy, completeness, or usefulness of any information, apparatus, product, or process disclosed, or represents that its use would not infringe privately owned rights. Reference herein to any specific commercial product, process, or service by trade name, trademark, manufacturer, or otherwise does not necessarily constitute or imply its endorsement, recommendation, or favoring by the United States Government or any agency thereof. The views and opinions of authors expressed herein do not necessarily state or reflect those of the United States Government or any agency thereof.
\end{abstract}

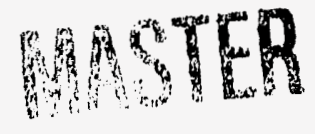




\title{
RELIADILITY' COMPARISON OF VARIOUS NUCLEAR PROPLLSION CONFIGURATIONS FOR MARS MISSION
}

\author{
Donald R. Segna \\ Department of Energy \\ Field Office, Richland Washington \\ P.O. Box $550 \mathrm{~N} / \mathrm{S}$ A 5.90 \\ Richland, WA 99352
}

(509) $376-8989$

\author{
Jeifery E. Dagle \\ Pacific Northwest Laboratory \\ P.O. Box 999 N/S $155-19$ \\ Richland, WA 99352 \\ (509) $375-3629$
}

\author{
William F. Lyon, III \\ Westinghouse Hanford Company \\ P. O. BOx 1970 W/S L5.02 \\ Richland, WA 99352 \\ (509) $376-8869$
}

\begin{abstract}
Abstrict
Currently, trade-offs are being made among the various propulsion systems being considered for the Space Exploration Initiative (SED missions. It is necessary to investigate the reliability aspects as well as the efficiency, mass savings and experience characteristics of the various conirgurations. Reliability is a very important factor for the SEI missions because of the long duration and because problems will be fixed onboard. The propulsion options that were reviewed consist of nuclear thermal propulsion (NTP), nuclear electric propulsion (NEP) ind various configurations of each system. There were four configurations developed for comparison with the NTP as baselined in the Synthesis (1991): 1) NEP, 2) hybrid NEP(NTP, 3) hybrid with power beaming, and 4) NTP upper stage on the heavy lift launch vehicle (HLLV). The comparisons were based more or less on a qualitative review oi complexity, stress levels and operations for each of the four configurations. Each configuration included a pressurized NEP and an NTP ascent stage propulsion system for the Mars mission
\end{abstract}

\section{INTRODUITION}

As indicated in the Synthesis Group Report nuclear thermal propulsion (NTP) for the Mars Transfer vehicle was selected on the basis of its substancially increased efficiency, safety, readiness, and its cost effectiveness in comparison to chemical propulsion. Reliability was only reviewed indirectly through safety, efficiency, etc. The intent of this paper is to extend the review of the various propulsion configurations that might be available for use on the SEI missions. Four configurations were developed. They include NEP, NTP/NEP hybrid, hybrid with laser power beaming, and finally using NTP as an upper stage on the HLLV.

A chemical propulsion comparison with NTP has been completed (Segna, 1991) and will not be repeated here. This comparison looked at those parumeters such as complexity, stress levels, and operational difficulties that have a propensity of affecing reliability. Reliability as used in these comparisons relates to the ability to accomplish the mission and return the crew safely. While these parameters do not comprise a classic reliability study, they can be used effectively in the conceptual design phase when trade studies are being performed. It was the practice of Apollo and Shuttle program managers when selecting a propulsion system, that orbit mass and even cost was allowed to be compromised in order to enhance reliability'. Obviously, a concept with more experience should have a high priority, however, systems with less experience but less complexity and with lower stress levels should also be considered. Higher reliability guided the decision to utilize storable, pressurized, and hypergolic propulsion systems for the Apollo space propulsion engine on the Command and Service Module, the descent and ascent engines on the Lunar Excursion Module, and the orbital maneuvering system on the Orbiter. These decisions were made even with a sacrifice in efficiency and mass savings that would have been afforded by the various cryogenic propulsion systems.

Importance of Propulsion Syctem Reliability

For the Nars mission, there is probably no partial success for the main propulsion maneuvers. The propulsion maneuvers have to star on time and continue for the required duration. For instance, there is no practical backup to the Mars orbit insertion maneuver using an impulse maneuvering sysiem. A free return, as was planned in the initial Apollo Wissions in the event of a no-go at lunar orbit insertion, is not practical for Wars orbit insertion. The reason is that a short duration trip to Mars is necessary to minimize the galactic radiation effects and deconditioning during the lengthy, zero gravity period. The short duration trip times are not compatible with a frae return because there is unreasonable excess velocity upon arriving at Mars. Even if free returh, along with the longer trans Viars time were acceptable, the excessive duration for the return leg, two years or longer, is undesirable. In addition, proper operation of the propulsion system is required in other instances such as the trans-Earth injection maneuver 
leaving .Yars and the braking maneuver just prior to entering the Earth's atmosphere. Even a partial bum in either situation could be a major problem. Theretore, a highly reliable propulsion system is imperative and will be a major factor in the final selection of the propulsion system.

\section{Assumptions}

This study makes the assumption that with increased complexiry, stress levels and/or the operational requirements of a system, with all else equal, the less reliable that system becomes.

At the design phase, increased complexity and stress levels, in themselves, do not decrease reliability because designers can accommodate them. If NASA said, "design to 0.9999," that is what the designer would do, but in acturity the as-built and as-operated may have an entirely different reliability factor than that predicted from design. Many factors can compromise the predicted reliability such as how the organization makes decisions. How do they allow information to be communicated? How does the designer integrate changes made in one area to insure those changes do not affect other systems? Are the specifications right? How good is the suppliers' QA program? Is the fidelity of the test programs adequate? Is the training program complete, etc.?

Below are items that illustrate some of the consequences of these factors:

- The Challenger accident may be considered an organizational problem. The information "not to launch" was there, but was not communicated to the proper staff members. This case illustrates the point above, that complexity is not the whole story. The solid rocket booster is a simpler system than the SSME's and was expected to have a very high reliability -. after the fix it may be, but for that particular launch condition it was not. The problem could have been circumvented if the test program had been of higher fidelity, without compromising the predicted reliability. Simplifying the SRB would have circumvented the problem. This could have been accomplished by making the booster in one piece, thereby avoiding o-ring failure. An example of the reliability of a simple system is the RTG nuclear isotope power supply.

- On Apollo 13 the reason for the LOX unk explosion was traced to a checkout procedure problem. Procedures were misread and DC instead of $A C$ voltage was applied to a circuit inside the oxygen tank overloading the circuit and causing it to short. When the circuit was energized in space the accident happened.

- The Hubble telescope didn't have high enough fidelity tests to see the error in the mirror grinding.

- Sometimes you get lucky. Apollo 8 POGO (propellant oscillations) was a design problem. While it was successful, if design margins hadn't added favorably, the thrust structure probably would have failed.

These examples are included to stress that if the system ignores good judgement, predicted reliability is worth no more than the paper the prediction was written on. Good judgement must prevail, and a thorough ground and flight test program must be conducted to screen any possible built-in problem(s).

So how is the comparison going to be valid relative to complexity? S:r.ply, the more complex a system the higher probability that "Murphy" will cause a problem. Also, every part, component, and system has a finite time to failure. We may not know what that time is, but we can say that the probability of failure will increase with complexity. Again, the Challenger accident is a case in point if the SRB had not been segmented, as mentioned atove, there would not have been an o-ring to fail.

Equating increase in stresses on a system to lower reliability is not an easy relationship. One ystem can be designed for $1000 \mathrm{~K}$ and the other for $3000 \mathrm{~K}$. As with complexity, either system can be desigried to the same reliability. Lat's look at factors where higher stresses might compromise reliability:

- Usually there is less experience at the higher stress level. Designers have to resort to using newer and more exotic materials as the stress levels are increased.

- The higher the system is stressed the greater the chance a failure will cause secondary damage. For example, failure of higher pressure systems creates higher speed projectiles; higher temperatures create more chemical reactivity, and higher temperatures increases heat transfer, likewise with higher voltage, cte. 
- A specified safery factor for a higher stressed system usually has a higher penalty mass and/or cost than the same safery factor for a lower stressed system. Since mass and cost are always under scrutiny, it is a greater probability that the higher stressed system will have a lower safety factor thus the potential to be less reliable.

\section{Chemical Vs VTP Assumption}

This comparison was previously completed under the same basis included in this paper. The result was the NTP has a very high potential for being more reliable than chemical, therefore, NTP as used in the Synthesis Report is the baseline for this study. Also, because of its higher reliability, NTP will be used in two other applications such as the ascent stage for Mars and a smaller version in conjunction with NEP in a hybrid mode. In addition, it was shown that a pressurized NTP is even simpler and is used in all the NTP configurations.

These configurations begin with the Synthesis Report NTP as the baseline. The first configuration developed for comparison replaced the NTP with a pressurized NEP and an NTP replaced the Mars ascent stage $\mathrm{H}_{2} \mathrm{O}_{2}$ cryogenic propulsion system. Next, a rclatively small NTP was added to the NEP configuration and is referred to as the hybrid followed by adding power beaming and finally adding pressurized NTP as the upper stage to the HLLV.

It did not appear that the NEP alone would be potentially more reliable than the NTP because of added complexity, so the hybrid and the $\mathrm{pc}$ wer beaming were added for further analysis. The NTP upper stage was added separately and though not included in all the comparisons, but because of its much higher efficiency and simplicity it is considered for this review.

These four configurations are applied to a Mars mission and are summarized in Table 1. Each succeeding configuration builds on the previous configuration.

\section{Cemparison}

The preceding configurations were then reviewed with respect to complexity, stress levels, and operations and then compared in Tables 2 through 5. Guidelines used for the comparisons are as follows:

- Each of the four configurations builds on the previous concepts.

- Benefits and adverse items will be listed compared to the previous concept. NTP will be considered the baseline and all the comparison items will be in the NEP column. For the NEP Plus Hybrid configuration, NEP will be the baseline and NEP Plus Hybrid will contain all the comparison items etc. This way the adverse items and the benefits are additive for each configuration change.

- Ascent stage will be NTP and pressurized (no propellant pumps). Also, reduces "g" build-up as propeliants are used.

- NEP propellant tanks will be pressurized (some increase in mass but reduces complexity).

- Minor comparison items are ignored. 
TABLE 1. Configuration Summary

\begin{tabular}{|c|c|c|c|c|c|}
\hline $\begin{array}{c}\text { MISSION } \\
\text { PHASE }\end{array}$ & $\begin{array}{c}\text { SYNTHESIS } \\
\text { ITP } \\
\end{array}$ & IEP & PLLS HYBRID & $\begin{array}{c}\text { PLLS } \\
\text { POWER } \\
\text { BEAMING } \\
\end{array}$ & $\begin{array}{l}\text { PLLS HLLV } \\
\text { PRESS. NTP } \\
\text { LPPER STAGE } \\
\end{array}$ \\
\hline $\begin{array}{l}\text { Basic Concept } \\
\text { Launch } \\
\text { LEO Ops }\end{array}$ & $\begin{array}{c}\text { Split/sprint } \\
\text { HLLV-250MT }\end{array}$ & $\begin{array}{l}\text { Same } \\
\text { Same }\end{array}$ & $\begin{array}{l}\text { Same } \\
\text { Same }\end{array}$ & $\begin{array}{l}\text { Same } \\
\text { Same }\end{array}$ & $\begin{array}{l}\text { Single mission } \\
\text { HLLV - 350MT }\end{array}$ \\
\hline unmanned & Assy for TMII & $\begin{array}{l}\text {-Assy LEO } \\
\text {-Spiral to escape }\end{array}$ & Same. & $\begin{array}{l}\text {-Dock components } \\
\text { to OTVe \& pwr/bm }\end{array}$ & $\mathrm{NH}$ \\
\hline manned & Assy for TMI & $\begin{array}{l}\text {-Assy, veh. \& dock } \\
\text { to OTVe } \\
\text {-Crew board taxi }\end{array}$ & Same & $\begin{array}{l}\text {-Dock components } \\
\text { to OTVe \& pwt/bm } \\
\text {-Crew board taxi }\end{array}$ & Same \\
\hline $\begin{array}{l}\text { Staging } \\
\text { unmanned }\end{array}$ & NA & NA & $\mathrm{NA}$ & $\begin{array}{l}\text {-Beam OTV/veh. to } \\
\text { Li \& assy. }\end{array}$ & $\mathrm{NA}$ \\
\hline manned & $\mathrm{NA}$ & $\begin{array}{l}\text {-OTV Spiral to L1 } \\
\text {-Followed by crew } \\
\text { taxi to Ll }\end{array}$ & Same & $\begin{array}{l}\text {-Beam OTV/veh to } \\
\text { L1 \& assy. } \\
\text {-Followed by crew } \\
\text { taxi to L1 }\end{array}$ & Same \\
\hline $\begin{array}{l}\text { TMI } \\
\text { unmanned }\end{array}$ & NTP & Spiral to escape & Same & Same & $\mathrm{NA}$ \\
\hline manned & NTP & $\begin{array}{l}\text {-Unciock OTV } \\
\text {-Taxi Dock } \\
\text {-Crew xfer } \\
\text {-Spiral escape }\end{array}$ & $\begin{array}{l}\text {-Undock OTY } \\
\text {-Taxi Dock } \\
\text {-Crew xfer } \\
\text {-Small NTP }\end{array}$ & Same & Same \\
\hline $\begin{array}{l}\text { Trans Mars } \\
\text { Mars Capture }\end{array}$ & Coast & NEP & same & Same & Same \\
\hline $\begin{array}{l}\text { unmanned } \\
\text { manned }\end{array}$ & $\begin{array}{l}\text { NL } \\
\text { NTP }\end{array}$ & $\begin{array}{l}\text { Spiral to LMO } \\
\text {-Spiral to medium } \\
\text { Mars orbit }\end{array}$ & $\begin{array}{l}\text { NEP spiral } \\
\text {-NEP braking } \\
\text {-Small NTP capure } \\
\text { HMO }\end{array}$ & $\begin{array}{l}\text { Same } \\
\text { Same }\end{array}$ & $\begin{array}{l}\text { NA } \\
\text { Same }\end{array}$ \\
\hline \multicolumn{6}{|l|}{$\begin{array}{l}\text { Mars Orbltal } \\
\text { Operation }\end{array}$} \\
\hline unmanned & $\begin{array}{l}\text {-Undock TEI } \\
\text { propellant } \\
\text {-Prepare for } \\
\text { descent. }\end{array}$ & $\begin{array}{l}\text {-Undock MTV/NEP } \\
\text { \& TEI propellant } \\
\text {-Split NEP to be } \\
\text { comm sat. } \\
\text {-Prepare for des }\end{array}$ & $\begin{array}{l}\text {-Same except } \\
\text {-Spiral descent stage } \\
\text { to LMO }\end{array}$ & $\begin{array}{l}\text {-Same except } \\
\text {-Split NEP to be } \\
\text { comm \& beam } \\
\text { satellite } \\
\text {-Beam OTV \& des } \\
\text { stg to LiHO }\end{array}$ & $\mathrm{NA}$ \\
\hline Descent: & $\begin{array}{l}\text {-Dock w/MTV \& } \\
\text { TEI propellant } \\
\text {-Prepare for } \\
\text { descent. }\end{array}$ & $\begin{array}{l}\text {-Dock w/MTV/NEP } \\
\text { \& TEI propellant } \\
\text {-Prepare for des }\end{array}$ & $\begin{array}{l}\text {-Des.to circ LMO } \\
\text { with small NTP }\end{array}$ & Same & $\begin{array}{l}\text {-Same except } \\
\text {-Split redundant } \\
\text { syst. to be comm \& } \\
\text { beam satellite. }\end{array}$ \\
\hline $\begin{array}{l}\text { Descent: } \\
\text { unmanned }\end{array}$ & -Descent by cryo & Same & Same & Same & NA \\
\hline manned & -Descent by cryo & $\begin{array}{l}\text {-Same except from } \\
\text { medium orbit }\end{array}$ & $\begin{array}{l}\text {-Same except from } \\
\text { LWO }\end{array}$ & Same & Same \\
\hline $\begin{array}{l}\text { Surface } \\
\text { Operation }\end{array}$ & $\begin{array}{l}\text {-Short or long } \\
\text { duration }\end{array}$ & Same & Same & $\begin{array}{l}\text {-Same except } \\
\text { surface power is } \\
\text { beamed }\end{array}$ & Same \\
\hline Ascent & -Ascent by cryo & $\begin{array}{l}\text {-Same except to } \\
\text { medium orbit by } \\
\text { NTP (asc, stage) }\end{array}$ & $\begin{array}{l}\text {-Same except to } \\
\text { Li10 }\end{array}$ & Same & Same \\
\hline TEI & NTP from LMO & $\begin{array}{l}\text {-NEP spiral to } \\
\text { escape }\end{array}$ & Small NTP.2 burn & Same & Same \\
\hline $\begin{array}{ll}\text { Trans Earth } \\
\text { Earth Capture }\end{array}$ & $\begin{array}{c}\text { Coast } \\
\text { Direct entry }\end{array}$ & $\begin{array}{l}\text { NEP } \\
\text {-Same except from } \\
\text { Gigh L1 } \\
\text { - - ise taxi to retum } \\
\text {-Possiole reuse }\end{array}$ & $\begin{array}{l}\text { Same } \\
\text { Same }\end{array}$ & $\begin{array}{l}\text { Same } \\
\text { Same }\end{array}$ & $\begin{array}{l}\text { Same } \\
\text { Same }\end{array}$ \\
\hline
\end{tabular}


- Very Large radiators

- Much smaller engines but more of them

- More lines and valving

- High current lines

- Requires separate launch for crew and taxi vehicle

- Large propellant tank required on the NTP ascent stage

- Requires jettison of NTP on ascent stage
- Eiminates separate power supply

- Smaller and/or fewer propellant tanks

- Lass radiacion shielding requirements

- Reduced structural requirements (less thrust)

- Lass precise reactor control mechanism

- Eliminate need for separate comm sat.

- Minimum storage requiremenis for photovoltaic power (standby or backup power) at Ll siaging point

- Reduces " $\mathrm{g}$ " loading due to propellant usage .. eliminates staging or wide range of throttling

\section{STRESS LEVEIS}

- Higher temperaures in engine

- High electrical currenis

- Higher magnetic fields

- Vehicle spends long time in Van Allen Belts

- Increase radiation dosage from NTP ascent stage
- Nluch lower thrust levels

- Lower tank and engine pressures

- Less propellant slosh

- Lower temperature in reactor

- Much lower pressure levels in reactor

- Reduced level debris field

- Reduced mission duration

- Less galactic ray exposure

- Liss probability to solar flare

- Winimum atomic oxygen

- Reduces refrigeration requirements over straight $\uparrow$ ITP (less fuel mass)

\section{OPERATIONS}

- Large radiator deployment

- Greater mdiator shadowing/thermal control operations

- Continuous propulsion on-time operations

- Spiral out to escape at mass adds $>20$ days
- . Winimum docking of propellant tanks

- Larger launch window's from Earth and Mars

- Nore abort capability

- Reduced trip times

- Longer Mars stay time for short duration stay missions

- Less Mass in LEO less assy operations

- Combining comm with MTV reduces number of separate satellites to manage

- No nuclear operations near LEO

- Il staging reduces communication link complexity (reduces TDRS requirements)

- Vo orbital decay

- Back contamination can be accommodated at L1. Requires more time $(\sim T$ days longer + contamination clan up)

- Furher mass to LEO reduced by not carrying crew ra:ntry vehicle to M Mars and back

TABLE 3. NEP Plus Hybrid (Small NTP) Summary

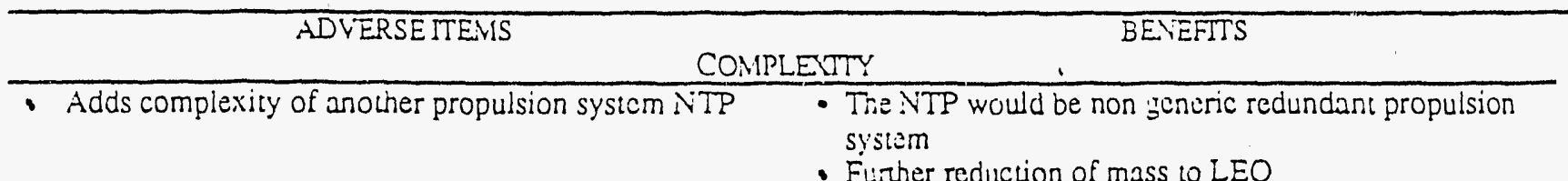




\section{STRESS LEVEL}

- Trip times turcher reduced

- Further reduction in galactic ray and probability of solar flare exposure

- Greatly reduced time in Van Allen Belts

\section{OPER.ATTONS}

- Less Nass in LEO iurther reduces ass:' operatio.s

- Mission duration further reduced

- Two different types of propulsion systems to guard acainst generic problems

TABLE 4. NEP Plus Power Beaming Summary

\section{ADVERSEMEMS}

\section{COMPLEXTTY}

BENEFITS

- Acids power ceaming transmilters and receivers

- Adds large ridiator

- Requires power beaming to OTV from Earth and Mioon

- Precise control for power beaming acquisition and racking
- Furher reduction of mass to LEO

- Eliminates need for separate surface prime power

- Redundancy is extemal to vehicle for some power and propulsion phases at Earth, Moon and Mars

\section{STRESS LEVELS}

- Trip umes further reduced

- Further teduction in galactic ray' and probability of solar flare exposure

\section{OPERATIONS}

- More radiator shadow/thermal control requirements

- Less Mass in LEO further reduces assy operations

- Wider launch windows at Earth and Mars

- Ll staging with beaming enhances reusable crew taxi which could be common with Mars ascent stage

- Commonality with lunar operations

- Enhances robotic operations because line-of-sight coverage from synchronous orbit is almost half the globe.

- Creiv excursions are also enhanced

TABLE 5. Plus NTP Upper Stage HILV Summary

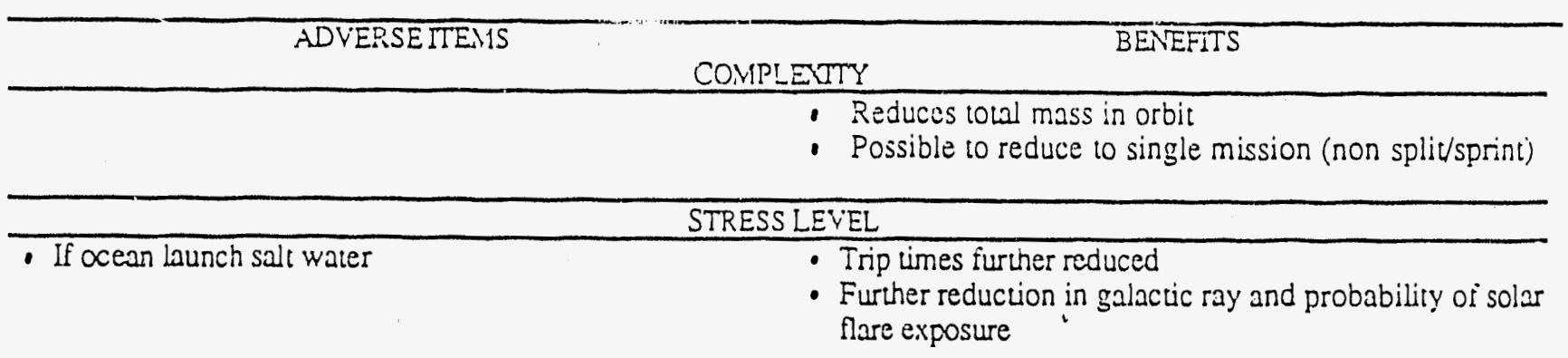


- Way launch from ocean

- Public opinion against nuclear
- Less assembly requirements in orbit

- Wider launch window's at Earth and Mars

- Can vary launch latitude and azimuth if ocean launch

- Less stringent launch abort requirements If ocean launch, non split/sfrint capability if hybrid, power beam and L1 staging point used

- Non split/sprint, possible to use Mars excursion vehicle as Life boat per Apollo 13

- Eliminates double missions (manned \& unmanned) on succeeding launch opdortunities

\section{CONCIUISIONS}

The NTP in a pressurized and somewhat reduced chamber pressure mode is a very simple propulsion system and has the potential of being very reliable. Replacing the cryogenic chemical ascent stage with an NTP system, using it in a hybrid mode with NEP and even as an upper stage of the launch vehicle, should increase the acrual reliability of the Mars mission.

There are two major draw backs for the NEP configuration: very large radiators and long duration in the Van Allen belts for much of the spacecraft. To counter the drawbacks, there are many more benefits but of a lesser impact. Without a more detailed swdy, judging the potential reliability difference would be very subjective.

Adding the hybrid adds no measurable adverse items since a redundant propulsion system is required regardless. The different propulsion concepts are desirable and eliminate a generic problem making both propulsion systems inoperable. Power beaming does add complexity because of the ransmitting antennas along with the large radiators needed to cool the antennas. However, the benefits of eliminating the surface prime, power equipment, the ability to be power rich, and to provide easily distributed power to exploring vehicles giving them unlimited range, will weigh heavily in the trade-off studies. The use of NTP for the upper stage of the HIL V may be precarious because of the public opinion against nuclear, but the repored (to the Synthesis Group) $60 \%$ increase in payload is extremely favorable. Also, the higher potential reliability over a cryogenic propulsion system, is most desirable. Especially since the Uranium 235 fuel is relatively safe (free of fission products and from transuranics) until the upper stage is started.

There are sufficient benefits when compared to adverse items that show NEP in a hybrid configuration with power beaming, should be included in the Mars technology trade-off studies. The added mission flexibility, powe: rich capability, and reduced trip times are very favorable. The blinders were on to take a qualitative look at the re/ ability comparison; therefore, the next effort should include the readiness level of the technology, the development $s$. hedule, and quantitative levels for both the adverse and benefit items. It is important to note the use of pressurized NTP for the hybrid and the Mars ascent stage propulsion systems and the use of LI as the staging point for TEI and Mars return. It keeps from having to take the reentry vehicle to Mars and back; it also affords back contamination processing if required.

\section{Acknowledgements}

This work was performed at the Department of Energy's Field Office, Richland, Washington. I gratefuly acknowledge the assistance of Joan Segna and Edward Coomes of the Pacific Northwest Laboratory, Richland, Washington, and the critique of Roy Rumery.

\section{Refierences}

Segna, D. R., 1991. "Reliability Comparison of Nuclear with Chemical Propulsion for Mars Mlission," AIAd 91. 3629, American Institute of Aeronautics and Astronautics, New York, New York.

Synthesis Group. 1991. "America at the Threshold," Synthesis Group. 

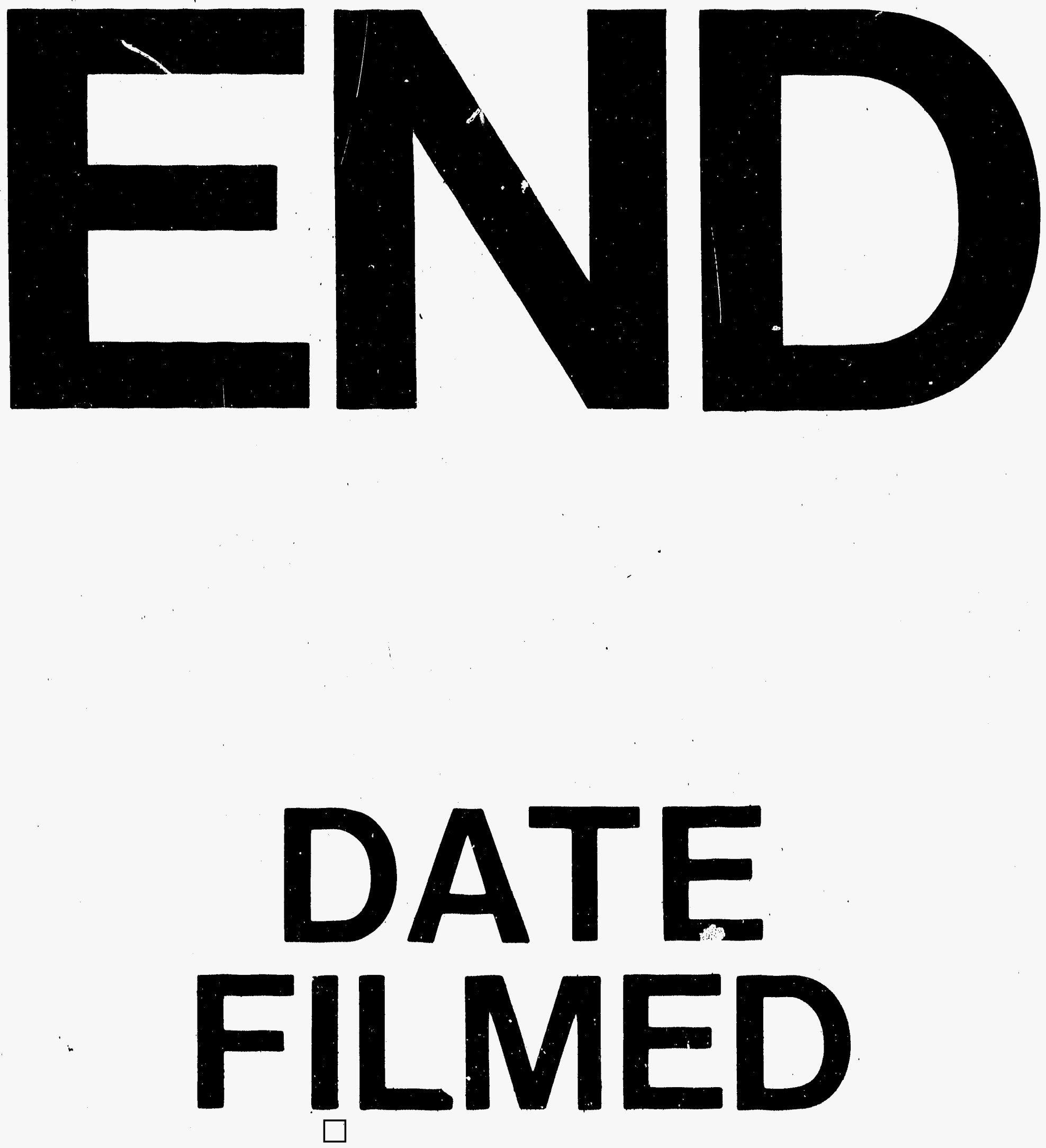

1

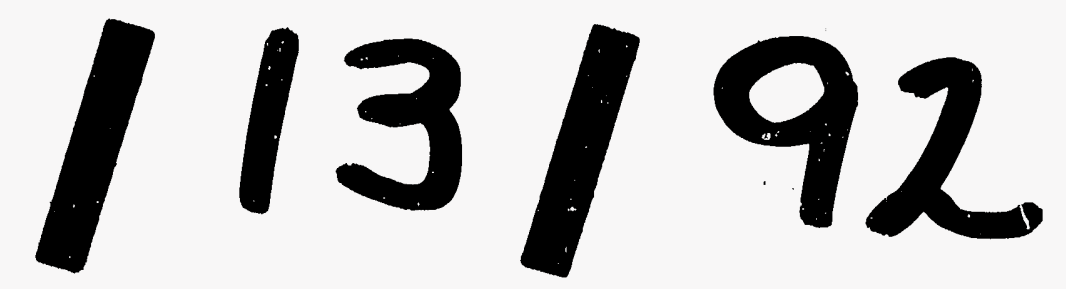


